\title{
Determinan Minat Individu Menjadi Pengemudi Kendaraan Online
}

\author{
Ervilia Agustine Wiharsianti \\ Erviliaggs@gmail.com, \\ Akuntansi, Universitas Ahmad Dahlan \\ Kahfi Fikrianoor \\ kahfifikri@gmail.com, \\ Akuntansi, Universitas Ahmad Dahlan \\ Listia Nur Aini \\ Listianura@gmail.com, \\ Kesehatan Masyarakat, Universitas Ahmad Dahlan \\ Amir Hidayatulloh \\ amir.hidayatulloh@act.uad.ac.id, \\ Akuntansi, Universitas Ahmad Dahlan
}

\begin{abstract}
ABSTRAK
Tantangan bisnis di era digital membawa perubahan tantangan bisnis dan gaya hidup. Era digital membawa perubahan gaya hidup menjadi instan sehingga masyarakat menghendaki mobilitas yang lebih cepat dan efisien. Sehingga, fenomena ini mendorong para pengusaha untuk memenuhi kebutuhan konsumen, dan salah satunya adalah perusahaan Go-Jek. Profesi menjadi G0-Jek tidak hanya diminati oleh kalangan yang memiliki pendidikan rendah, akan tetapi mahasiswa bahkan orang yang memiliki pendidikan tinggi pun ingin menjadi driver online. Sehingga, dari fenomena ini penelitian ini mencoba menggali faktor-faktor apa saja yang mendorong individu untuk menjadi pengemudi online. Populasi dari penelitian ini adalah pengemudi online. Teknik penggambilan sampel dari penelitian ini menggunakan convience sampling. Pengumpulan data dalam penelitian ini dengan melakukan wawancara kepada pengemudi kendaraan onlime. Responden dalam penelitian ini berjumlah 10 responden. Penelitian ini memperoleh hasil bahwa kontrol perilaku persepsian, norma subyektif, dan sikap terhadap perilaku merupakan faktor-faktor yang mempengaruhi individu untuk menjadi pengemudi kendaraan online.
\end{abstract}

Kata Kunci: Kontrol Perilaku persepsian, Norma Subyektif, dan Sikap

\section{ABSTRACT}

Business challenges in the digital age bring in business and lifestyle challenges. The digital age brings lifestyle changes into an instant so that people want faster and more efficient mobility. Thus, this phenomenon encourages entrepreneurs to meet the needs of consumers, and one of them is the Go-Jek company. The profession of becoming G0-Jek is not only in demand by people who have low education, but students and even people who have higher education also want to be a online driver. So, from this phenomenon this study tries to explore what 
factors drive individuals to become online drivers. The population of this study is the online driver. The sampling technique of this study uses convience sampling. Collecting data in this study by conducting interviews with drivers of online vehicles. Respondents in this study were 10 respondents. This study results that control of perceived behavior, subjective norms, and attitudes toward behavior are factors that influence individuals to become drivers of online vehicles.

Keywords:perceived behavior control, subjective norms, attitude

\section{PENDAHULUAN}

Tantangan bisnis diera digital ini semakin masif membawa perubahan dalam tantangan bisnis dan gaya hidup, mulai dari pesaing-pesaing baru, inovasi produk, mobilisasi yang serba cepat. Hal ini akan mendorong perubahan model bisnis. Teknologi membuat tatanan gata hidup berubah menjadi instan, sehingga masyarakatingin mobilisasinya cepat dan efisien. Hal ini membuat para pengusaha bisnis mencoba mengimbangi permintaan konsumen dengan megembangkan teknologi pada usaha bisnisnya. Salah satunya Perusahaan GoJek yang beroperasi di bidang transportasi.

Sebelum transportasi online berkembang, Go-Jek telah lebih dulu mengawalinya. Awal berdirinya sempat menjadi perbincangan masyarakat. GoJek menghadirkan aplikasi gojek online dan mengubah cara pemesanan kendaraan dengan cepat dan mudah, cukup dengan smartphone. Aplikasi ini mengkalkulasi biaya perjalanan dan pengemudi akan menjemput penumpang dimanapun sesuai dengan yang tercantum dalam pesanan pengemudi.

Munculnya ojek online ini disambut baik oleh masyarakat sekitar. Aplikasi ini dianggap sebagai jawaban dari permasalahan padatnya jalanan. Namun, keberadaan ojek online ini membawa pertentang bagi ojek konvensional. Hal ini karena keberadaan ojek online dianggap merebut esksitensi ojek konvensional. Akan tetapi, seiring berjalannya waktu, pertentangan dari ojek online menyurut. Sebaliknya, semakin banyak yang tertarik dan berpindah haluan untuk menjadi pengemudi ojek online dari berbagai latar belakang. Bisnis ojek online ini memberikan peluang kerja masyarakat yang memiliki kendaraan, Surat ijin mengemudi, dan smartphone yang tidak atau sedang mencari pekerjaan.

Tidak ada yang mengira profesi pengemudi ojek online akan dilamar oleh ribuan orang. Mitra pengemudi Go-Jek mencapai 900.000. Pada awalnya individu ingin menjadi pengemudi kendaraan online karena desakan ekonomi, namun sekarang mahasiswa pun ada yang berprofesi sebagai sampingan bahawa pemasukan bulannya. Tidak hanya mahasiswa, pengemudi ojek online bahkan ada yang berasal dari kalangan yang sudah mapan dari segi ekonominya (Bohang, 2017).

Ojek merupakan jasa yang diberikan terhadap masyarakat untuk orang yang ingin berpergian namun malas dan tidak ingin menggunakan kendaraan pribadi. Menurut data survei dari Yayasan Lembaga Konsumen Indonesia pada 5-16 april 2017 dengan melibatkan 4.668 responden Keberadaan ojek sangat membantu pemerintah dalam mengurangi jumlah kemacetan dan jumlah pengangguran yang ada. Sebuah pencapaian yang mengesankan, terutama untuk 
profesi yang selama ini dianggap kelas pinggiran oleh kebanyakan orang (Tempo.co, 2017).

Salah satu sumber ketidakefisienan layanan tukang ojek adalah masa tunggu yang terlalu lama. Ojek online dengan keunggulan aplikasinya yang real time mampu memotong masa tunggu itu. Masa tunggu dapat ditekan hingga nyaris nol. Dengan proses seperti itu, maka tingkat produktivitas pengojek naik signifikan. Hal ini yang menguntungkan bagi pelanggan untuk menghemat waktu mereka.

Salah satu dampak yang terjadi ketika produktivitas naik, otomatis income juga bisa melesat ke level yang lebih tinggi. Hal ini yang menyebabkan banyak orang yang sangat tertarik dengan pekejaan pengemudi ojek online. Keunggulan aplikasi (digital apps) dapat dimanfaatkan untuk memperdayakan ekonomi kaum kelas pinggiran yang masih minim.

Dengan adanya ojek online ini mengubah industri yang tidak diatur menjadi sistem yang mudah dan efesien. Dari hasil survei awal, kami tertarik melakukan penelitian yang berjudul determinan minat individu menjadi pengemudi kendaraan online.

\section{TINJAUAN PUSTAKA}

\section{Ojek}

Ojek merupakan salah satu transportasi alternatif yang ditawarkan di Indonesia. Dalam (Kamus Besar Bahasa Indonesia, 2008)kata ojek diartikan sebagai sepeda atau sepeda motor yang digunakan untuk mengantar penumpang dengan cara diboncengkan dibelakang dengan imbalan upah. Dalam gaya hidup masyarakat sekarang, ojek dibagi menjadi dua,yaitu konvensional dan online. Perusahaan ojek online yang aktif beroperasi saat ini antara lain; Go-jek, Uber, grab, jeger, Teknojek dan lain-lain.

Kata konvensional berarti berdasarkan konvensi (kesepakatan) umum,seperti adat, kebiasaan, kelaziman, tradisional (Kamus Besar Bahasa Indonesia, 2008), sedangkan kata online dalam bahasa indonesia disebut daring, berdasar Kamus Besar Bahasa Indonesia yang merupakan akronim dari dalam jaringan, memiliki arti terhubung melalui jejaring komputer, internet,dan sebagainya. Dari pengertian diatas dapat ditarik kesimpulan bahwa ojek konvensional merupakan jasa ojek yang masih tradisonal sehingga dalam menggunakan layanannya tidak perlu secara online. Sedangkan ojek online merupakan jasa transportasi yang dalam pelayanannya menggunakan jaringan internet.

\section{Teori Tindakan Beralasan (Theory Reasoned Action)}

Theory of Reasoned Action (TRA) menghubungkan antara keyakinan(belief), sikap(attitude), $\operatorname{kehendak(intention)~dan~perilaku(behavior).~}$ 
Martin FishbeindanAjzenadalah orang yang pertama kali memperkenalkan teori ini. Jika ingin mengetahui apa yang akan dilakukan seseorang maka cara terbaiknya yaitu mengetahui kehendak seseorang terlebih dahulu, karena kehendak itu merupakan predikator terbaik dalam perilaku(Jogiyanto, 2007).

Teori ini mempunyai konsep penting yaitu fokus perhatian (salience), yang artinya mempertimbangkan sesuatu yang dianggap penting terlebih dahulu. Menurut (Jogiyanto, 2007)kehendak (intention) ditentukan oleh sikap dan norma subyektifnya. Intensi atau niat merupakan fungsi dari dua determinan dasar, yaitu yang pertama sikap individu terhadap perilaku (merupakan aspek personal) dan yang kedua persepsi individu terhadap tekanan sosial untuk melakukan atau untuk tidak melakukan perilaku yang disebut dengan norma subyektif ini menurut pendapat dari (Jogiyanto, 2007). Jadi perilaku menurut Theory of Reasoned Action (TRA) dipengaruhi oleh niat, dan niat dipengaruhi oleh sikap dan norma subyektif. Hal itu pula yang menjadikan teori ini sebagai landasan untuk mengetahui determinan mina tindividu menjadi pengemudi kendaraan online. Sikap itu sendiri dipengaruhi oleh keyakinan akan hasil dari tindakan yang telah yang dilakukan dan norma subyektif dipengaruhi oleh keyakinan akan pendapat orang lain serta motivasi untuk menaati pendapat tersebut.Jadi jika seseorang akan melakukan suatu perbuatan yang dianggap itu positif maka ia akan percaya bahwa orang lain juga menginginkan agar ia melakukannya.

\section{Norma Subyektif (Subjective Norm)}

Norma Subyektif(Jogiyanto, 2007)adalah persepsi atau pandangan seseorang terhadap kepercayaan-kepercayaan orang lain yang akan mempengaruhi minat untuk melakukan atau tidak melakukan perilaku yang sedang dipertimbangkan. Pengemudi kendaraan online tidak terlepas dari kegiatan mengambil keputusan untuk berperilaku. Keputusan yang akan diambil seorang pengemudi ojek online yang akan diambil dengan pertimbangan diri sendiri maupun pertimbangan dari orang lain yang dianggap penting. Dengan demikian pertimbangan dari orang lain dapat memberikan dorongan atau semangat untuk mengambil keputusan menjadi pengemudi kendaraan online.

\section{Sikap}

Sikap menurut dari beberapa pakar psikologi merupakan evaluasi kepercayaan (belief) atau perasaan positif atau negatif dari seseorang jika harus melakukan perilaku yang akan ditentukan. Pendapat (Allport, 1935)mengartikan attitude yaitu sikap terhadap objek tertentu yang merupakan sikap pandangan atau sikap perasaan, akan tetapi sikap tersebut disertai dengan kecenderungan untuk bertindak sesuai dengan objek. Jadi ide yang berkaitan dengan emosi yang 
mendorong pengemudi kendaraan online untuk melakukan tindakan-tindakan tertentu dalam situasi sosialnya, yaitu sikap itu sendiri.

\section{Teori Tindakan yang direncanakan (Theory of Planned Behavior)}

Teori ini merupakan pengembangan dari Theory Reassoned Action perbedaannya hanyapada TPB ditambah satu faktor yang berkaitan dengan kontrol, yaitu Perceived Behavior Control (PBC). Theory of Planned Behavior (TPB) mengemukakan bahwa tindakan manusia dibimbing oleh tiga macam faktor, yaitu keyakinan (belief) tentang hasil perilaku dan evaluasi terhadap hasil perilaku (behavior belief), keyakinan tentang harapan normatif dari orang lain, motivasi untuk menuruti dari adanya harapan tersebut (normative belief), dan keyakinan tentang hadirnya faktor yang memfasilitasi atau menghambat perilaku, serta presepsi adanya power pada faktor tersebut (control belief).

Persepsi kontrol perilaku (Perceived Behavioral Control) perasaan seseorang mengenai mudah atau sulitnya mewujudkan suatu perilaku tertentu, Ajzen menjelaskan tentang perasaan yang berkaitan dengan perilaku kontrol dengan cara membedakannya dengan locus of control atau pusat kendali yang dikemukakan oleh Rotter's. Pusat kendali berkaitan dengan keyakinan seseorang yang relatif stabil dalam segala situasi. Persepsi kontrol perilaku dapat berubah tergantung situasi dan jenis perilaku yang akan dilakukan. Pusat kendali berkaitan dengan keyakinan individu bahwa keberhasilannya melakukan segala sesuatu tergantung pada usahanya sendiri (Rotter's, 2010).

\section{METODE}

\section{Sumber Data}

Sumber data dalam penelitian ini adalah data primer. Data primer dalam penelitian ini adalah pengemudi ojek online. Dalam mengumpulkan data, peneliti melakukan wawancara secara langsung baik dalam suasana formal maupun nonformal pada para pengemudi ojek online yang merupakan subjek penelitian. Sebagaimana yang dikatakan oleh (Azwar, 2010)bahwa "Data primer adalah data yang diperoleh langsung dari subjek penelitian sebagai sumber informasi yang dicari". Wawancara formal yang peneliti maksud adalah meminta waktu khusus untuk melakukan wawancara, sedangkan wawancara non formal maksudnya wawancara berlangsung di kegian-kegiatan lain.

\section{Jenis Data}

Penelitian ini merupakan jenis penelitian kualitatif. Data yang dikumpulkan merupkan data kualitatif. Maka, teknik pengumpulan data dengan melakukan wawancara mendalam. Kegiatan wawancara ini bersifat lentur, tidak terstruktur secara ketat dan menggunakan pertanyaan yang umum agar peneliti 
berpeluang mendapatkan informasi yang seluas-luasnya tanpa membatasi partisipan dalam mengungkapkan pikiran dan pendapatnya. Informasi dari partisipan tersebut lalu diruncingkan untuk mendapatkan garis besar dari permasalahan. Disamping itu, kegiatan wawancara dilakukan secara non formal agar pihak partisipan tidak merasa sedang diinterogasi.

\section{Metode/Desian Penelitian}

Teknik analisis data yang digunakan dalam penelitian ini adalah model interaktif, yang meliputi kegiatan pengumpulan data, reduksi data, penyajian data, penarikan serta pengajuan kesimpulan ( mendeleyin Miles). Teknik analisis data dalam penelitian disajikan pada gambar 1 berikut.

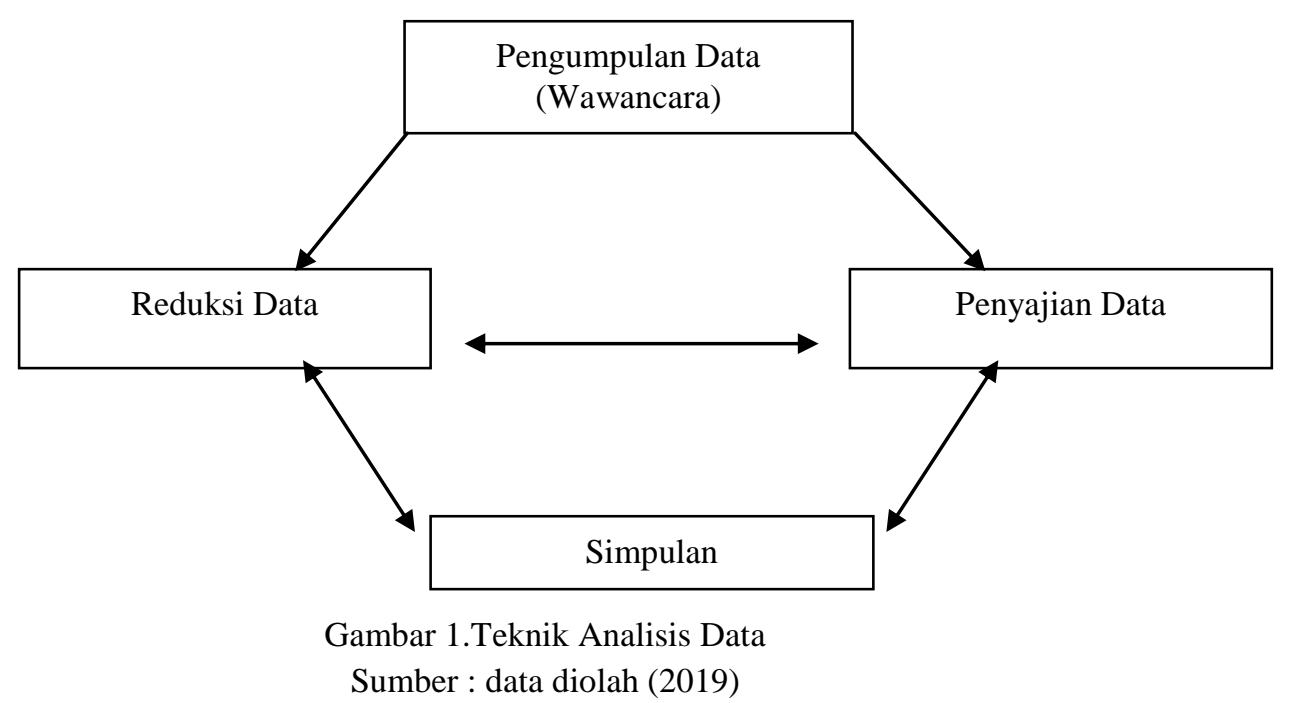

\section{HASIL DAN PEMBAHASAN}

\section{Deskripsi Responden}

Berdasarkan pendidikan terakhir responden, dapat di simpulkan bahwa pengendara kendaraan online berasal dari berbagai jenjang pedidikan bahkan salah satu responden berasal dari sarjana yang notabene adalah orang yang memiliki pendidikan tinggi. Tabel pendidikan terakhir responden disajikan pada tabel 2 berikut. 
Tabel 2. Pendidikan terakhir responden

Sumber : data diolah (2019)

\begin{tabular}{|c|c|}
\hline Pendidikan & Responden \\
\hline TK & 1 \\
\hline SD & 1 \\
\hline SMP & 1 \\
\hline SMA & 5 \\
\hline D3 & 1 \\
\hline S1 & 1 \\
\hline
\end{tabular}

Usia responden dalam penelitian ini paling banyak pada rentan usia 30 sampai 39 tahun yaitu sebanyak 7 responden, sedangkan responden dengan rentan usia 20 sampai 29 tahun berjumlah 1 responden dan responden dengan rentan usia 40 sampai 49 tahun berjumlah 2 responden. Tabel usia responden disajikan pada tabel 3 berikut.

Tabel 3. Rentan usia responden

Sumber : data diolah (2019)

\begin{tabular}{|c|c|}
\hline $\begin{array}{c}\text { Rentan } \\
\text { Usia }\end{array}$ & Responden \\
\hline $20-29$ & 1 \\
\hline $30-39$ & 7 \\
\hline $40-49$ & 2 \\
\hline
\end{tabular}

Tabel 3. Hasil Wawancara Yang Telah Direduksi

\begin{tabular}{|c|c|c|}
\hline Kode & Pertanyaan dan Jawaban & Verbatim \\
\hline & $\begin{array}{l}\text { Mas pertama kali kenal gojek itu dari mana ya? } \\
\text { Apa yang mendorong mas jadi driver online? }\end{array}$ & \\
\hline A & $\begin{array}{l}\text { Saya pertama kali kenal dari social media seperti } \\
\text { facebook, itu internet selebihnya sama teman. Yang } \\
\text { pertama itu untuk kebutuhan hidup mas, dorongan diri } \\
\text { sendiri selebihnya. Soalnya gak ada kerjaan lain. } \\
\text { Soalnya kan nyari kerja sekarang susah gitu. Jadi ya } \\
\text { saya menggunakan apa yang saya bias aja. }\end{array}$ & $\begin{array}{l}\text { (Kontrol Perilaku } \\
\text { Persepsian) }\end{array}$ \\
\hline B & $\begin{array}{l}\text { Dari temann, iya teman . Dari temen ngajak saya jadi } \\
\text { ojek online. Itu karena pendapatan emang lebih dari } \\
\text { pekerjaan lama }\end{array}$ & (Norma Subyektif) \\
\hline
\end{tabular}




\begin{tabular}{|c|c|c|}
\hline Kode & Pertanyaan dan Jawaban & Verbatim \\
\hline $\mathrm{C}$ & $\begin{array}{l}\text { Dari keluarga. Kakak, kan, di Bekasi di sana kan dia } \\
\text { tahu informasi dari Jakarta to, Mbak, itu Jogja mau } \\
\text { buka. Karena gajinya lebih banyak, lebih besar. }\end{array}$ & (Norma Subyektif) \\
\hline $\mathrm{D}$ & $\begin{array}{l}\text { Ya karena yang di online itu kan biasanya tiap hari ada } \\
\text { pemasukan. Kalau di proyek itu kan kalau nggak ada } \\
\text { borongan nggak dapat uang, Mbak. }\end{array}$ & $\begin{array}{l}\text { (Kontrol Perilaku } \\
\text { Persepsian) }\end{array}$ \\
\hline $\mathrm{E}$ & $\begin{array}{l}\text { Yaa dia kan juga security, daripada kita Cuma setelah } \\
\text { selesai pulang jaga dari pada di rumah kita mendingan } \\
\text { ngojek online aja yang bisa di sempet sempetin bisa } \\
\text { ketemu sama temen-temen juga }\end{array}$ & $\begin{array}{c}\text { (Kontrol Perilaku } \\
\text { persepsian ) }\end{array}$ \\
\hline $\mathrm{F}$ & $\begin{array}{l}\text { Ya, cuma tahu, gimana caranya, daftarnya gitu. Kalo } \\
\text { kerjaan dulu Ya duitnya lebih sedikit dari Gojek. } \\
\text { Kalau dibanding apa misalnya gajinya sehari kalau } \\
\text { proyek } 60 \text { ribu. Itu aja nggak boleh istirahat, panas. Ini } \\
\text { capek, ya, istirahat nggak ada yang marahin. }\end{array}$ & $\begin{array}{c}\text { (Kontrol Perilaku } \\
\text { Persepsian) }\end{array}$ \\
\hline G & $\begin{array}{l}\text { Saya tahu sendiri dari social media dan sebelumnya } \\
\text { sebelum menjadi driver Gojek saya menjadi sebuah } \\
\text { karyawan swasta dan di situ udah } 14 \text { tahun pindah- } \\
\text { pindah pekerjaan dan akhirnya saya memiliki keluarga } \\
\text { dan memiliki anak kecil di situ saya merasa kalau jadi } \\
\text { karyawan swasta waktu saya kurang enak sama } \\
\text { perusahaan sendiri dan sama bos sendiri karena } \\
\text { kebanyakan ijin kalau punya anak kecil. Karena itu } \\
\text { saya memilih jadi driver ojek online karena waktu } \\
\text { yang fleksibel bisa menyesuaikan keadaan di rumah. }\end{array}$ & $\begin{array}{l}\text { (Sikap terhadap } \\
\text { Perilaku) }\end{array}$ \\
\hline $\mathrm{H}$ & $\begin{array}{l}\text { Tahu gojek dari teman, pertama ngajak setelah itu ya } \\
\text { saya setelah itung-itung ternyata dari gaji per bulannya } \\
\text { kalau buat bekerja itu ya lumayan. Tapi kalau di Gojek } \\
\text { itu yang besar itu bukannya gajinya tapi incomenya. } \\
\text { Karena dulu itu bonusnya besar, sekarang bonusnya } \\
\text { agak sedikit kecil tapi tetep aja incomenya lebih besar } \\
\text { Gojek. }\end{array}$ & (Norma subyektif) \\
\hline
\end{tabular}




\begin{tabular}{|c|l|c|}
\hline Kode & \multicolumn{1}{|c|}{ Pertanyaan dan Jawaban } & Verbatim \\
\hline I & $\begin{array}{l}\text { Enggak. Inisiatif sendiri, daftar. Yo nganu. Sing jelas } \\
\text { ki yo yang penting saya punya pekerjaan begitu aja. } \\
\text { Punya penghasilan yang jelas itu. Biar rejekinya dateng } \\
\text { dari segala penjuru ngono lho. }\end{array}$ & $\begin{array}{c}\text { (Sikap Terhadap } \\
\text { Perilaku) }\end{array}$ \\
\hline $\mathrm{J}$ & $\begin{array}{l}\text { Dari temen mbak, temen juga yang ngajak gabung . } \\
\text { Jadi driver gini lebih fleksibel mbak, dari segi } \\
\text { pendapatan pun lebih tinggi jadi ojek gini daripada } \\
\text { kerjaan yang dulu. }\end{array}$ & (Norma Subyektif) \\
\hline
\end{tabular}

Sumber : data diolah (2019)

Tabel 3 menunjukan bahwa empat dari 10 responden menjadi pengemudi online karena kontrol perilaku persepsian seperti pendapatan yang tinggi, kepuasaan berkumpul dengan teman serta waktu yang lebih fleksibel.Selain kontrol perilaku persepsian, menjadi pengemudi online juga dipengaruhi oleh norma subjektif seperti teman dan keluarga (hal ini diungkapkan oleh empat responden).Sedangkan, dua responden menyatakan bahwa repsonden menjadi pengemudi online memang karena berinisiatif sendiri dan tidak memiliki pekerjaan. Hasil penelitian ini didukung oleh penelitian sebelumnya yaitu (Ratnadi \& Widanaputra, 2019); (Pradipta \& Suprapti, 2013); (Intan, Parwati, Prayudi, \& Kurniawan, 2019)menyatakan bahwa kontrol perilaku persepsian, norma subjektif, dan sikap merupakan beberapa faktor yang mendorong individu untuk menggunakan teknologi.

\section{SIMPULAN}

Niat untuk menjadi pengemudi online ditentukan oleh norma subjektif, kontrol perilaku persepsian, dan sikap terhadap perilaku. Faktor yang paling dominan yang mendorong individu untuk menjadi pengemudi online adalah kontrol perilaku persepsian, seperti pendapatan yang tinggi, kepuasan ketika berkumpul dengan teman serta waktu yang fleksibel. Selain itu, individu menjadi pengemudi online juga ditentukan oleh norma subjektif, seperti teman dan keluarga. Faktor lain yang mendorong individu untuk menjadi pengemudi online adalah sikap terhadap perilaku, misal insisiatif dirinya sendiri, dan tidak ada pekerjaan lain.

Keterbatasan dari penelitian adalah penelitian ini memiliki validitas eksternal rendah. Hal ini karena penelitian ini menggunakan metode wawancara. Sehingga, penelitian selajutnya dapat menggunakan metode survei, agar memperoleh validitas eksternal tinggi. 


\section{DAFTAR PUSTAKA}

Allport, G. W. (1935). Attitudes dalam Handbook for Social Psychology. Mass :

Clarc University Press.

Azwar, syarifudin. (2010). Metode penelitian. yogyakarta: Pustaka Pelajar.

BOHANG, F. K. (2017, December 12). Berapa Jumlah Pengguna dan Pengemudi

Go-Jek? Kompas.Com. Retrieved from

https://tekno.kompas.com/read/2017/12/18/07092867/berapa-jumlah-

pengguna-dan-pengemudi-go-jek

Intan, W., Parwati, G., Prayudi, M. A., \& Kurniawan, P. S. (2019). ANALISIS

FAKTOR-FAKTOR YANG MEMPENGARUHI PENGGUNAAN SISTEM

INFORMASI E-PARKING ( Studi Empiris : Masyarakat Pengguna E-

Parking di Tabanan ), 1, 184-195.

Jogiyanto. (2007). Sistem Informasi Keperilakuan. Yogyakarta: Andi Offset.

Kamus Besar Bahasa Indonesia 2008. (2008).

Pradipta, I. G. S., \& Suprapti, N. W. S. (2013). Pengaruh Sikap Dan Norma

Subyektif Terhadap Niat Calon Pemilih Di Kota Denpasar Untuk Memilih

Partai Demokrat Dalam Pemilu Legislatif Tahun 2014. Jurnal Manajemen,

Strategi Bisnis, Dan Kewirausahaan, 07(1), 29-38.

Ratnadi, N. M. D., \& Widanaputra, A. A. G. P. (2019). Pengaruh Persepsi

Kegunaan, Kemudahan Penggunaan dan Norma Subyektif pada Minat

Berperilaku Penggunaan E-Billing. Jurnal Ilmiah Akuntansi Dan Bisnis,

14(2), 169. https://doi.org/10.24843/jiab.2019.v14.i02.p03

Rotter's. (2010). Rotter's dalam Raco, JR, 2010).

Tempo.co. (2017, May 25). Transportasi Online, YLKI: 72,6 Persen Gunakan GoJek. Metro.Tempo.Co. Retrieved from

https://metro.tempo.co/read/874563/transportasi-online-ylki-726-persengunakan-go-jek/full\&view=ok 